\title{
Certificates for High-Quality Cartographic Products
}

\author{
Temenoujka Bandrova $^{\mathrm{a},}{ }^{*}$, Miljenko Lapaine $^{\mathrm{b}}$, Silvia Marinova ${ }^{\mathrm{c}}$ \\ ${ }^{a}$ Bulgarian Cartographic Association, email: tbandrova@abv.bg \\ ${ }^{b}$ Croatian Cartographic Society, email: mlapaine@geof.hr \\ ${ }^{c}$ Bulgarian Cartographic Association, email: marinova_silvia@abv.bg \\ * Corresponding author
}

\begin{abstract}
The study is inspired by questions that students and teachers ask during past experiments that the authors have carried out. The users who represent Bulgarian and Croatian schools are invited to evaluate existing maps and draw their own maps. This research focuses on cartographical mistakes and how they impact user's understanding of the map. We don't aim to show or explain all cartographic mistakes. The examples are chosen arbitrarily and do not claim to provide an exhaustive list of the problems.

Online maps which hold a significant market share provide cartographic information in various thematic areas for different kind of users. Producers of all world map platforms try to cover all necessary information in a similar way and do not consider user's age, cultural, professional and knowledge diversity. Similar behaviour is observed with the production of traditional maps where various cartographic mistakes can be pointed.
\end{abstract}

To respond to these observations, Bulgarian and Croatian cartographic associations created rules and conditions under which a cartographic product can receive a Certificate for high-quality map / atlas / other cartographic product.

Keywords: Maps, Cartographic mistakes, Certificate, High-quality map

\section{Introduction}

Nowadays, the use of GIS becomes more and more popular. The best result of data analysis is visualization by maps. Therefore, every child, student and person who has access and basic knowledge in GIS can create their map. The problem arises when publishers make such web and paper maps (where basic cartographic principles are not met) available to society.

The most popular and useful maps for public use are tourist maps. This is the reason why their market share increases constantly. The same maps attract publishers and "map-makers" without the needed qualification, experience or knowledge. Very often the results lead to inaccurate products and confused users. To make a differentiation between such publications and good cartographic products companies use the name "quality maps". This is to help them advertise their products (Quality Maps, 2011, Quality Maps \& More, 2019 and others). After making critical review and analysis of maps produced by different publishers, Andrew Wiseman (2015) concludes that "none of this means that all maps are bad, or that we should always be suspicious of them, or that only experts should make maps. Maps are inherently interesting and fun (so is geography!), but a little bit of thought and increased awareness of how they can manipulate or obscure is a good thing, too. Just like advertisements and political campaigns, we shouldn't trust maps (or the data behind them) inherently, but they can still be powerful, interesting and amusing”.
Cartographers can help in the process of creating a map and using it. The first step could be educating children how to use a map and later how to make a map. In many different research with children and students, cartographers find this common work as very useful because of understanding how users read, understand and think about the maps. Very often users' questions and ideas help map makers and cartographers to make better maps (Bandrova et al. 2010, Bandrova T., 2012). In similar research, we found the problem with maps in textbooks of geography and history. Some examples will be discussed below.

The step that national and international map agencies could make is to propose control, certificates or other activities which will differentiate quality maps created according to all cartographical aspects and rules. Bulgarian and Croatian cartographic societies have some experience on this topic and aim to make it more popular and useful in their countries and also to present this idea abroad.

\section{Definition and map elements}

With the usage of new technologies and the map out of its limits on paper, many definitions of map can be given. In all of them, however, lies the mathematical modelling of the real world and the conditional representations of objects and phenomena.

Here one of the definitions given in a Bulgarian textbook will be quoted. "The geographic map is a scaled image of the earth's surface (or part of it) on a plane by symbols. 
Each geographic map has three mandatory elements: mathematical (scale, geographic grid), geographic (objects shown by symbols), and auxiliary (title, legend)“ (Dermendzhieva S. et al., 2016). If we agree with this definition, the massive presence of "maps" without a scale and network of meridians and parallels (graticule), with no title or no legend defining the meaning of the symbols, is unexplained. The massive images mislead Bulgarian students that these are maps. They do not even meet the definition given in the same textbooks in which they are placed. Naydenov (2003) describes many mistakes that can be found in textbooks and atlases. Now atlases are not so often shown as bad examples but textbooks are still full of cartographical mistakes.

The problem is not only for Bulgarian textbooks. There are similar ones in many textbooks that can be found all over the world. Such "maps" can be found everywhere: in encyclopaedias, books, websites, documents, research papers (even presented in cartographic conferences). An example of the issues discussed above is shown in Figure 1. If we accept a more flexible definition of the map, then the schematic representation in Figure 1 can be called a map.

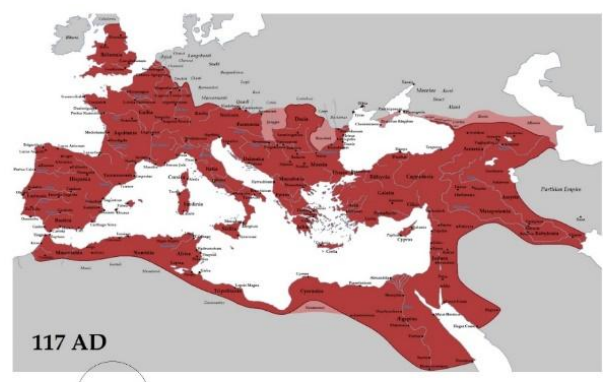

Figure 2.4: Map of the Roman Empire, 117 CE (Courtesy of Tataryn, Wikimedia Commons

Figure 1. A scheme defined as a map in textbook of World Regional Geography (Finlayson, C., 2019)

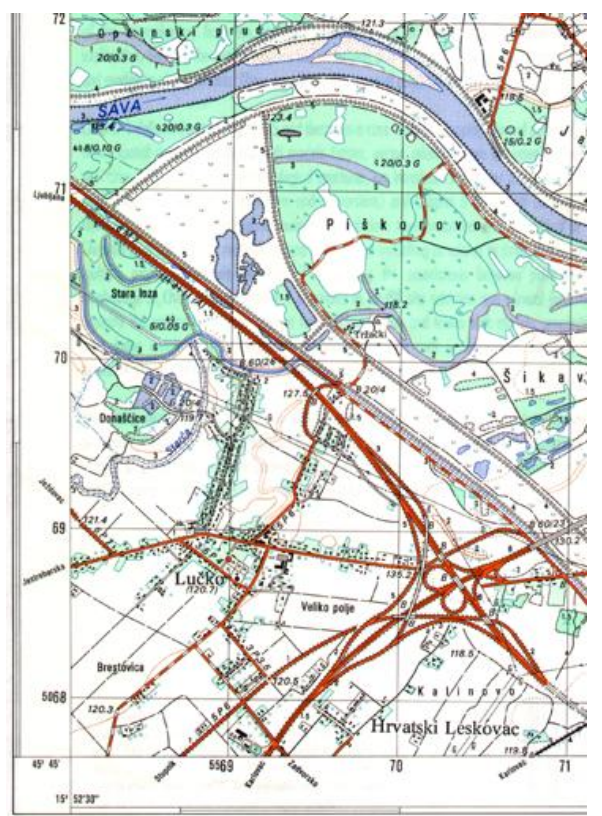

Figure 2. Part of a topographic map from a Croatian textbook of geography. The problem is not with the map, but with the description in the textbook saying that topographic maps include a network of parallels and meridians.
Even if an official map is published in the textbook, it does not have to mean that everything is fine. E.g. a section of the topographic map was printed (Figure 2) in a Croatian geography textbook for the fifth grade of primary school, but with the misinterpretation that the meridian and parallel networks were printed on all topographic maps. However, this is obviously not the case, because a coordinate network is printed, not the graticule.

\section{Country names on geographic maps}

States define two forms of use for their names - official and short. The official name is used when the state is spoken of as a legal entity and the short form is used when the state is referred to an economic or geographic area. In some countries, the official and short forms coincide, e.g. Czech Republic (currently), Ireland, Romania (Europa, 2017).

In the cartographic community, it is acceptable to use the short names of the countries on the maps. The question about the Republic of Macedonia (currently, North Macedonia) was clear about what had to be written on the Bulgarian maps, following the decisions of the government of the Republic of Bulgaria. In 1992 Bulgaria first recognized the independence of the Republic of Macedonia, under its constitutional name. The short name coincided with the official name. In some maps, however, the country is written as simply Macedonia. This is inaccurate as the name of Macedonia defines a historical - geographic area (see Figure 3) that goes beyond the borders of the country

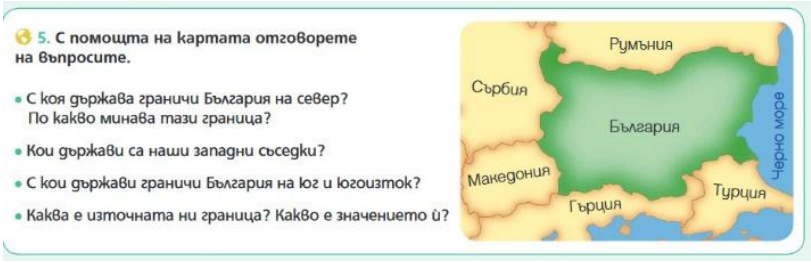

Figure 3. State Names on a map (Dermendzhieva S. et al., 2016)

The new Act on the State Survey and Cadastre of Real Estates in Croatia was published on 14 December 2018. Among other tasks, the Act regulates the registry of geographic names. The Commission for the Standardisation of Geographic Names will be constituted in Croatia for the first time in history. It is expected that this committee will be helpful in solving the questions of geographic names on Croatian maps. In the same time, Bulgarian commission for geographic names standardisation was established long time ago but it is not working effectively and this creates difficulties to all map producers and publishers who start to use the most popular rather than certified names in their cartographic products.

\section{Scale}

The scale, as basic element of the map, is studied in geography classes for $5^{\text {th }}$ grade students. Perceiving it as a reducing factor in mapping and at the same time as a means of calculating real distances often makes difficulties to the learner. For example, in the electronic 
version of textbooks that contain scanned copies of paper, the use of numerical scale is unnecessary, as every change in the zooming of the image leads to a wrong perception of the scale (Figure 4).

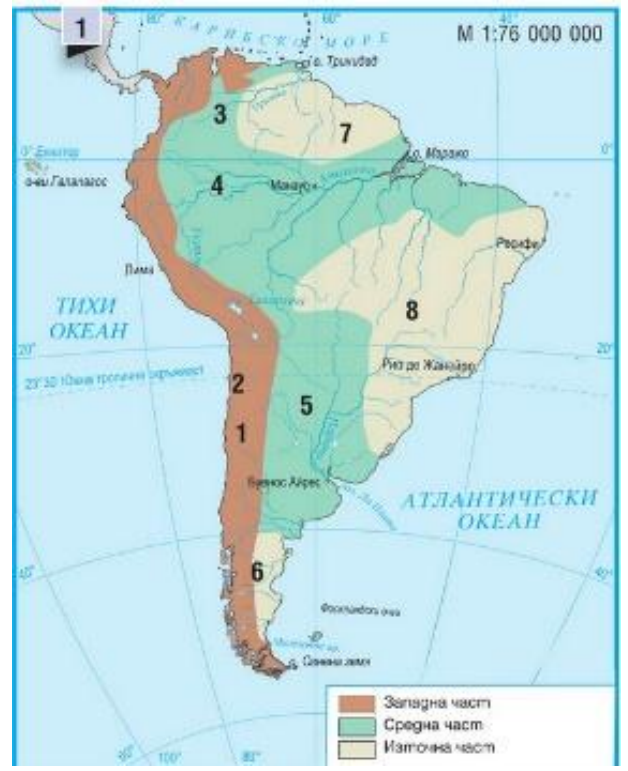

Figure 4. Using numerical scale in an electronic version of a textbook (Dermendzhieva S. et al., 2017 e-variant)

Another example shows that using maps with numerical scales in textbooks is also not recommended. This is valid mainly when map makers or cartographers do not have opportunities to check the final version of the textbooks before printing. Very often designers scale maps to fit into the pages. The images in Figure 5 show exactly the example that was described. The result could be misunderstanding about the scale or the length of different map features.
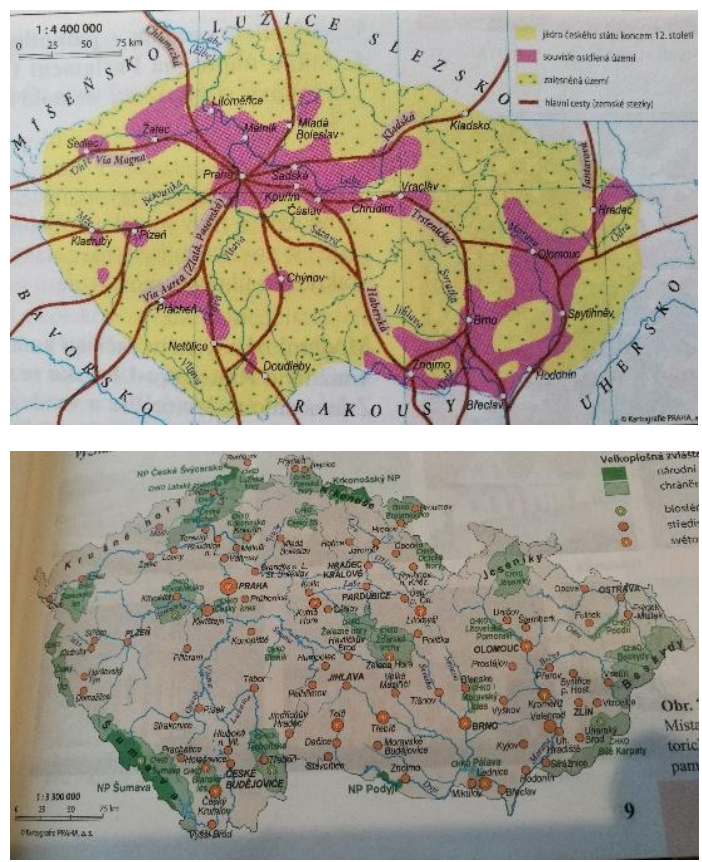

Figure 5. One and the same linear scale and different numerical one (In Czech textbooks on geography)
Another problem arises when the map was stretched or squeezed in one direction only. That often happens with the map of Croatia (Figure 6). Due to the natural circumstances, the Croatian territory fit nicely in a square. But, due to the clumsiness of "cartographer" it appears distorted, usually stretched in the west-east direction.

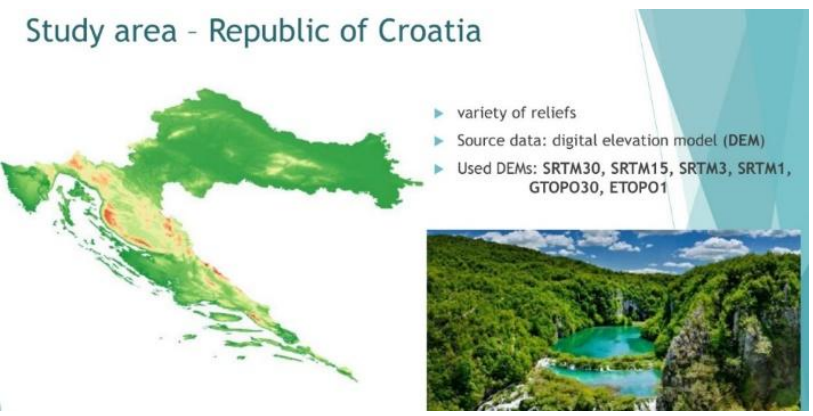

Figure 6. Distorted map of Croatia used in a conference presentation. The north-south and west-east dimensions of Croatia are approximately equal, while the Croatian territory was stretched in the west-east direction on this slide.

\section{Map orientation}

Meridians are the only lines on the map that point north and south directions. Often, maps published in textbooks have not a graticule. Describing the frames as directions of the world is wrong, except if the depicted area is in a normal cylindrical projection or one with straight horizontal parallels and vertical meridians. Often a North sign is also used in geographic maps, even in a combination with a graticule with curved meridians or meridians which are not parallel to the central one. Both cases are unacceptable. In Figure 7 the North sign on the map is valid only for a current meridian and not for the whole map.

When compiling, the maps are north oriented, and this applies in all cases only to the central meridian, which is always a straight line, and when it is in the centre of the map.

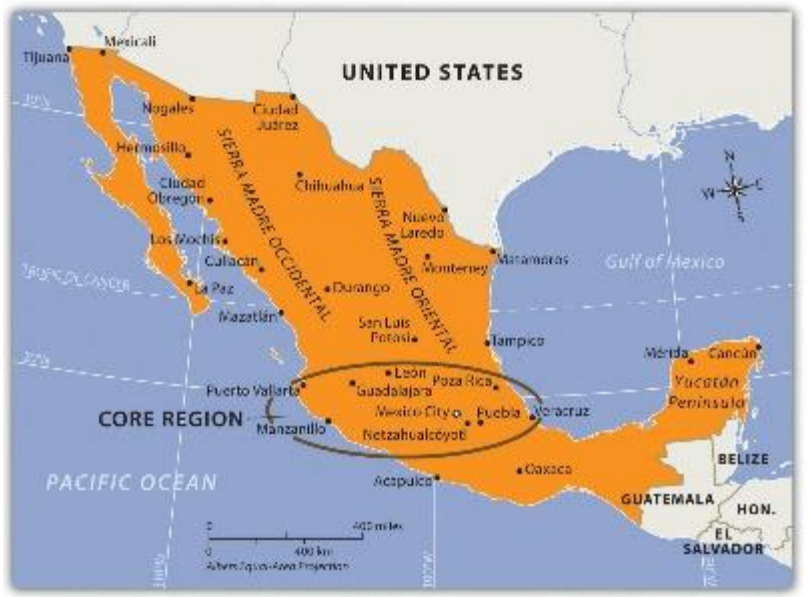

Figure 7. Example of an inappropriate usage of the symbol of North (Minneapolis, 2016) 


\section{Cartographic symbols}

Reading the map is difficult without knowing the legend. Different experiments with children of different ages reveal students' understanding of the subject. A larger or smaller symbol is identified with a larger or smaller scale, even when "zooming". In the schematic images called maps in geography textbooks, point and line contingency symbols of different size in the map and legend are often mistaken (see Figure 8). The symbols on the map must be described in the legend in the same type and size, otherwise, children may be misled.

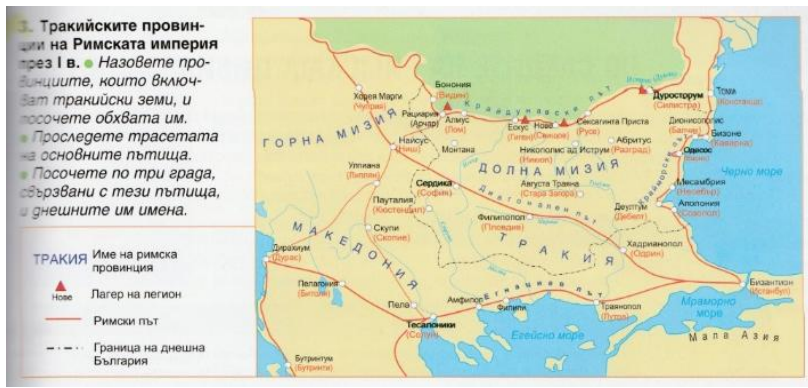

Figure 8. Different size of symbols used on map and legend (Lekov T. et al., 2016)

The described examples are only a part of the mistakes and inconsistencies between theory and images used in the textbooks as well as in some atlases. This leads to a misinterpretation of the elements used by cartography. We would like to point out the path that should be taken to remove them in the new editions, and to give guidance on how the mapmakers can check the quality of their cartographic works.

\section{Certificates}

A Map Review Form was published in Cartography and Geoinformation Journal, Croatia. The intention of the form was to determine whether a map qualifies for a certificate of the Croatian Cartographic Society. The form consists of 24 questions (see Appendix), starting with "Does the map title correspond to its content?" and ending with "Are map aesthetics adequate?". A reviewer may also consider other map elements, if they are present, including titles and designations of neighbouring sheets, object index (list), additional diagrams and graphs, multilingualism, inserted map, extended map, etc. If the map is a digital product, one needs to consider eight additional details, e.g. "What file format (pdf, tiff, jpeg, bmp, gif, ...) is the map in?" and "Is it possible to interact with the map?". A reviewer may also consider additional elements, if they are present, such as dynamic map, animation, sound and other multimedia capabilities. At the end of the form, a reviewer states the final opinion and recommendation, which may include steps necessary for the map to be certified or perhaps published in the Cartography and Geoinformation journal (Frangeš, 2016). Unfortunately, there has not been any interested cartographer so far and the form has not been tested yet.

Since 2017 Bulgarian Cartographic Association (BCA) issues certificates of quality for cartographic products. Certification is based on an expert assessment of a threemember committee. To obtain a certificate, cartographic products must meet 12 criteria of accuracy, reliability and high-quality design and presentation. The scientific committee evaluates whether the map projection is appropriately set and whether the map scale is correctly selected and noted. It is important that the represented objects and phenomena comply with the legend. Text label placing, colour design, and overall map design should meet the scientific principles of cartographic design and be consistent with the users' needs (BCA, 2017). Each reviewer gives an overall assessment of the cartographic product based on the 12 criteria. The criteria can be applied to various types of products - wall maps, map leaflets, atlases, globes, raised relief maps, 3D maps, digital maps and others. When a certificate is issued a special badge of Certificate of quality can be placed on the cartographic product (Figure 9).

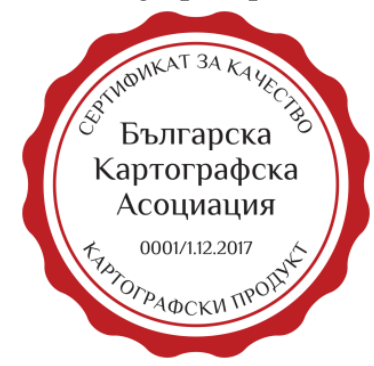

Figure 9. Badge for Certificate of quality issued by Bulgarian Cartographic Association

Each certified product receives a unique identification number including a serial number and date of issue. BCA maintains a database with information about the certified cartographic products, incl. serial number and date of issue of the Certificate, title of the cartographic product and type (paper map, atlas, etc.). Map scale and projection, language(s), format and number of pages are noted in special fields. The database contains also information about the author(s), publisher, date of issue, etc.

BCA meets understanding and support from its members and this idea is gaining popularity among Bulgarian map publishers. BCA prepares cooperation on this topic with the National Library and other institutions.

With these certificates publishers of maps, atlases or other cartographic products will avoid potential mistakes and inaccuracies and will also provide users with correctly presented cartographic information.

\section{Conclusions and remarks}

One of the best solutions on how to avoid cartographical mistakes in textbooks is to use separately atlases which are usually prepared by cartographic companies. Such example we can see in Czech textbook of Geography where authors suggest using of Atlas of the world and time zone map to find out the time difference between Russia's western and eastern borders (Demek J. and Malis I., 2008).

The aim of authors is to help map makers and organizations which produce and use cartographic products to create and use only high-quality products. Mistakes could be found and avoided. New higher quality 
products will be proposed on the market. Map users will find correct and high-quality information and will take the right decisions for their needs. The professional level of cartographers and map makers will arise in society, their work will be more important for everybody, everywhere, for every purpose.

Our main tasks are to make Certificates that indicate the quality of cartographic product popular. It should be proposed to international organizations like European grants offices for scientific products, to national governmental bodies like ministers of educations. If some changes in national laws specify using of the proposed certificate, good and positive results will come fast. International Cartographic Association could help in the process of popularisation with the establishment of some common rules for map creating, even to propose international certificate.

\section{References}

Bandrova T., Konecny M., Rusnakova M. (2010) Research of Students' Cartographical Knowledge in Early Warning and Crisis Management. In Geographic Information and Cartography for Risk and Crisis Management. Lecture Notes in Geoinformatics and Cartography. ISSN 1863-2246, ISBN 978-3-642-034411 Springer Heidelberg Dordrecht London New York, pp. 361-378.

Bandrova T. (2012) Cartographic Response to Changes in Teaching Geography and History, Maps for the Future. Lecture Notes in Geoinformation and Cartography, 2012, Volume 5, 203-217, DOI: 10.1007/978-3-64219522-8_17 Springer.

BCA (2017) Certificate of Quality of Cartographic Product issued by Bulgarian Cartographic Association, online available on 02.01.2019, https://cartographygis.com/sertifikat-za-kachestvo (In Bulgarian)

Demek J., Malis I. (2008) Zemepis Svetadilu pro zakladni skoly, SPN, Praha, ISBN 978-80-7235-383-5

Dermendzhieva S., Stoyanov, P., Sabeva P., Nikolova N., Peikova T. (2016) Geography and Economics 5. grade, Prosveta, ISBN 978-954-01-XXXX-X, online available on 10. 11.2017,

Europa (2017) Office of Publications of the European Union (Publications Office of the European Union) Interinstitutional guide for the preparation of publications, ISSN, 1821-5380, online available on 10 . 11. 2017, http: //publications.europa. eu / code / en / bg370100.htm

Finlayson, C. (2019) World Regional Geography, This work is licensed under a Creative Commons"Attribution-NonCommercial-

ShareAlike4.0Interna-tional" license, online available on 10.02.2019, http://caitiefinlayson.com/WRGTextbook.pdf

Frangeš, S. (2016) A Map Review Form / Recenzija karte, Cartography and Geoinformation / Kartografija i geoinformacije, Vol.15, No. 25, pp 132-135.
Gartner, G. (1998) About the Quality of Maps, Cartographic Perspectives, Journal of North America Cartographic Information Society, Number 30, Spring 1998 , pp. 38-46.

Lekov T., Boteva-Boyanova D., Nikolov A., Boseva M, (2016) History and Civilizations for 5th grade, Prosveta - Sofia, ISBN 978-854-01-3166-5

Minneapolis (2016) World Regional Geography: People, Places and Globalization, by University of Minnesota is licensed under a Creative Commons AttributionNonCommercial-ShareAlike 4.0 International License, except where otherwise noted, This Edition Adapted from a Work Originally Produced in 2012 by a Publisher Who Has Requested That It Not Receive Attribution., Mn, ISBN 13: 9781946135278, online available on 10.02.2019, https:/open.umn.edu/opentextbooks/textbooks/worldregional-geography-people-places-and-globalization

Naydenov, N. (2003) Work with Maps and Atlases in Primary Education, Geography Education 6/2003, 52-56

Penin R., Stoyanova V., Traykov T., Ivanov D. (2016) Geography and Economics 5. grade, BULVEST 2000, ISBN 978-954-18-1010-1

Quality Maps, Inc. 2011 http://qualitymaps.com/ (available on 4.03.2019)

Quality Maps \& More 2019

https://qualitymapsandmore.co.uk/ (available on 4.03.2019)

Tsankova, L., Dimov N., Lazarova E., Kotzev G., Bardarova G., Getova N. (2016) Geography and Economics for 5. Class, Prosveta plus, ISBN 978-619222-XXX, online available on 10. 11. 2017

Wiseman A. 2015. When Maps Lie, https://www.citylab.com/design/2015/06/when-mapslie/396761/ (available on 4.03.2019) 


\section{Appendix}

A MAP REVIEW FORM published in Cartography and Geoinformation, 2016, Vol.15, No. 25, pp 132-135

Map title:

1. Does the map title correspond to its content?

2. How large is the map (dimensions) and is the size adequate?

3. Is the applied map scale adequate?

4. Is the applied map projection adequate?

5. Does the map contain a coordinate grid and is it correct?

6. Does the map contain author and copyright data?

7. Is the issue number and publishing date (year) indicated on the map?

8. Does the map contain data on publisher and circulation?

9. Are the originals used to produce the map indicated on the map?

10. Is the represented area optimal?

11. Does the map contain all necessary topographic object groups (settlements, roads, water, vegetation, relief and borders)?

12. Is all necessary thematic content represented on the map?

13. Are all necessary toponyms provided on the map and is it done according to cartographic principles?

14. Is there a base map and is it adequate?

15. Is the map field optimal?

16. Are map elements arranged optimally?

17. Are adequate map graphic elements (cartographic signs, color, font) applied on the map?

18. Are relief and various relief forms represented optimally?

19. Does the map feature a legend and is it adequate?

20. Is map generalization adequate?

21. Is the map legible?

22. Is the map clear?

23. Are map geometry and content accurate?

24. Are map aesthetics adequate?

A reviewer may also look at other elements if they are present and applied on the map, including: titles and designations of neighbouring sheets, object index (list), additional diagrams and graphs, multilingualism, inserted map, extended map, etc.

If the map is a digital map on a CD or a similar medium and enclosed with Cartography an Geoinformation, one needs to consider:

1. What file format (pdf, tiff, jpeg, bmp, gif, ...) is the map in?

2. What kind of program platform is necessary to view the map?

3. What is the map resolution?

4. What is the file size (MB, GB)?

5. Does the map consist of layers?
6. Can the map be zoomed?

7. Is it possible to search the map?

8. Is it possible to interact with the map?

A reviewer may also look at additional elements, such as dynamic map, animation, sound and other multimedia possibilities if they are present on the map.

FINAL OPINION AND RECOMMENDATION

Is the map acceptable for publishing with Cartography and Geoinformation?

Overall map evaluation

Originality:

Degree of interest in the map:

Necessary steps for the map to be acceptable for publishing with Cartography and Geoinformation:

Date and location of review:

Reviewer's signature: 